\title{
Efek Suhu dan Injeksi Udara pada Penyisihan Limbah Pewarna Tekstil Remazol Red dengan Metode Elektrolisis Plasma
}

\author{
Tri S. Budikania ${ }^{1}$, Dian R. Suminar ${ }^{2}$, Eva F. Karamah ${ }^{2}$, Nelson Saksono ${ }^{2, *}$ \\ ${ }^{1}$ Politeknik AKA Bogor, Jl. Pangeran Sogiri No. 283, Tanah Baru, Bogor, 16154 \\ ${ }^{2}$ Departemen Teknik Kimia Fakultas Teknik Universitas Indonesia, Kampus Baru UI Depok, 16424 \\ *e-mail: nelson@che.ui.ac.id
}

\begin{abstract}
Abstrak. Limbah pewarna industri tekstil merupakan limbah cair yang sulit teroksidasi dan berbahaya bagi lingkungan. Radikal hidroksil $(\bullet \mathrm{OH})$ merupakan spesies yang sangat efektif dalam mengoksidasi berbagai limbah cair organik seperti limbah pewarna. Metode Elektrolisis Plasma sangat produktif menghasilkan radikal Hidroksil sehingga efektif dalam menyisihkan (mendegradasi) berbagai jenis limbah pewarna tekstil seperti Remazol Red. Penelitian ini bertujuan mengoptimalkan proses degradasi remazol red RB 133 dan konsumsi energinya menggunakan metode Elektrolisis Plasma melalui pengaturan suhu dan injeksi gelembung udara dalam larutan. Pembentukan $\mathrm{H}_{2} \mathrm{O}_{2}$ merupakan indikator pembentukan $\bullet O H$ pada reaksi Elektrolisis Plasma. Injeksi udara pada larutan limbah pewarna menurunkan arus listrik pada kurva karekateristik arus-tegangan. Kenaikan suhu larutan dari $45^{\circ} \mathrm{C}$ menjadi $75^{\circ} \mathrm{C}$ selama 10 menit reaksi tampa injeksi udara menurunkan konsumsi energi dari $229,9 \mathrm{~kJ}$ menjadi 219,5 kJ serta menurunkan produksi $\mathrm{H}_{2} \mathrm{O}_{2}$ dari 4,8 mmol menjadi 3,1 mmol. Sementara injeksi udara pada suhu $75^{\circ} \mathrm{C}$ selama 10 menit proses menurunkan konsumsi listrik hingga 28,5\% dan meningkatkan produksi $\mathrm{H}_{2} \mathrm{O}_{2}$ hingga 27,3\%. Namun demikian injeksi udara hanya meningkatkan degradasi Remazol Red sebesar 1,8\%. Suhu optimum dicapai pada $55^{\circ} \mathrm{C}$, dengan produksi $\mathrm{H}_{2} \mathrm{O}_{2}$ sebesar 5,7 mmol selama 30 menit. Injeksi udara udara mampu meningkatkan efektivitas proses. Hasil penelitian menunjukkan persen penyisihan mencapai 88,9\% dengan konsumsi energi sebesar 115,2 kJ dalam waktu 30 menit reaksi.
\end{abstract}

Kata kunci: elektrolisis plasma, remazol red, gelembung udara.

\begin{abstract}
Effect of Temperature and Air Injection on Degradation of Remazol Red Textile Dyes by Plasma Electrolysis Method. The textile dye waste is a liquid waste that is difficult to oxidize and dangerous for the environment. Hydroxyl radicals $(\bullet \mathrm{OH})$ are very effective species in oxidizing various organic liquid wastes such as Remazol Red. Plasma Electrolysis Method is very productive in producing Hydroxyl radicals, resulting in effective degradation of various types of textile dye waste such as Remazol Red. This study aims to optimize the degradation process of remazol red RB 133 and its energy consumption using the Plasma Electrolysis method through temperature regulation and injection of air bubbles in solution. The formation of $\mathrm{H}_{2} \mathrm{O}_{2}$ is used an indicator of the formation of $\cdot \mathrm{OH}$ in the Plasma Electrolysis reaction. The Air injection decreases the electric current on the current-voltage characteristic curve. The solution temperature increases from $45^{\circ} \mathrm{C}$ to $75^{\circ} \mathrm{C}$ for 10 minutes reaction without air injection were able to reduce the energy consumption from $229.9 \mathrm{~kJ}$ to $219.5 \mathrm{~kJ}$ and $\mathrm{H}_{2} \mathrm{O}_{2}$ production from $4.8 \mathrm{mmol}$ to $3.1 \mathrm{mmol}$. Meanwhile, the addition of air injection at $75^{\circ} \mathrm{C}$ within 10 minutes of reaction were able to reduce electricity consumption by $28.5 \%$ and increases $\mathrm{H}_{2} \mathrm{O}_{2}$ production by $27.3 \%$. However, the addition of air injection only increased the degradation of Remazol Red by $1.8 \%$. The optimum temperature was reached at $55^{\circ} \mathrm{C}$, with $\mathrm{H}_{2} \mathrm{O}_{2}$ production of $5.7 \mathrm{mmol}$ for 30 minutes. The addition of air injection has been shown to increase the effectiveness of the process. The results showed degradation percentage reached $88.9 \%$ with energy consumption of $115.2 \mathrm{~kJ}$ within 30 minutes of reaction.
\end{abstract}

Keywords: air injection, plasma electrolysis, remazol red.

Graphical Abstract

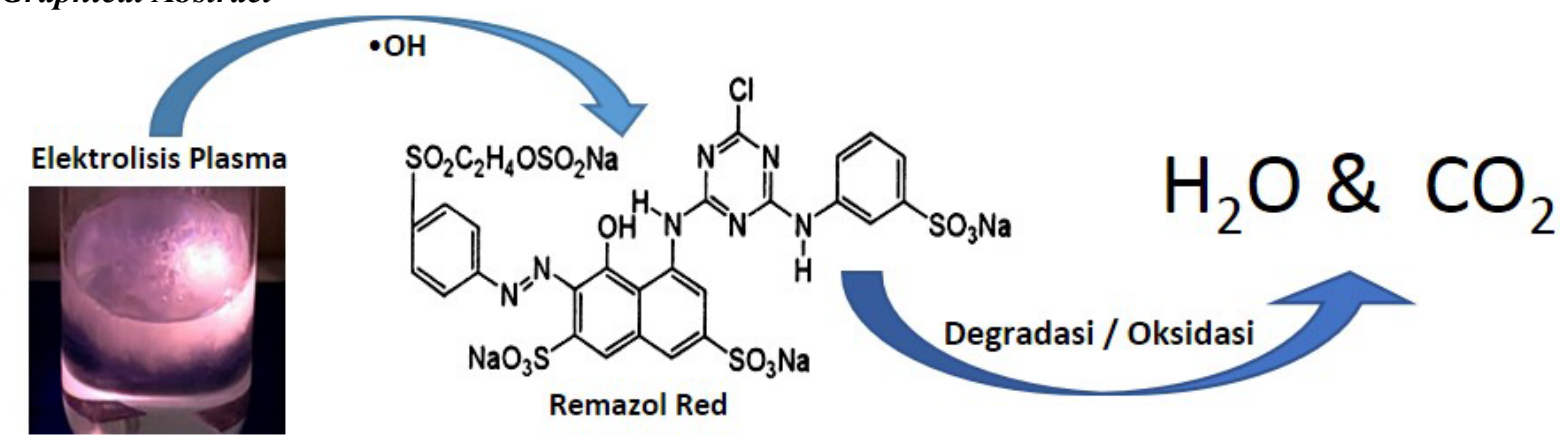




\section{Pendahuluan}

Industri tekstil merupakan industri yang berkembang pesat di Indonesia. Industri ini banyak menggunakan air untuk proses produksinya, diantaranya pencelupan, yaitu proses penambahan zat warna kedalam produk tekstil seperti serat, benang dan kain. Ogugbue dkk. (2011) menyatakan hampir 200 ribu ton zat warna terbuang setiap tahun selama proses pencelupan dan finishing. Berbagai polutan seperti sisa zat pewarna, senyawa organik dan surfaktan ditemukan dalam limbah tekstil. Zat pewarna merupakan salah satu sumber kontaminasi lingkungan karena kestabilan dan sifat toksiknya yang tinggi terhadap mahluk hidup di perairan serta efek karsinogenik terhadap manusia. Adanya sejumlah kecil zat pewarna terlihat jelas dan mempengaruhi kualitas air (Khairy dkk., 2016). Polusi zat pewarna akan meningkatkan kekeruhan, sehingga dapat menghalangi masuknya sinar matahari ke badan air dan mengganggu proses fotosintesis tanaman. Dibutuhkan perlakuan yang tepat untuk memastikan bahwa polutan aman dibuang ke lingkungan.

Ada beberapa teknik yang digunakan untuk menghilangkan zat warna dari limbah, seperti proses koagulasi, oksidasi, filtrasi dan biologis (biodegradasi). Koagulan yang biasa digunakan di industri seperti aluminum sulfat, feri klorida dan polialuminum klorida. Aplikasi bahan kimia ini menimbulkan dampak seperti meningkatnya konsentrasi logam dalam air, produksi lumpur beracun dalam jumlah besar serta berdampak bagi kesehatan (Lau dkk., 2015). Penghilangan zat pewarna dengan koagulan akan menghasilkan lumpur (sludge) dalam jumlah yang relatif besar, sehingga akan menimbulkan masalah baru pada unit pengolahan limbah (Manurung dkk., 2004). Ozon cukup efektif dalam menghilangkan warna yang disebabkan oleh dye larut air, terutama fiber acid dan reaktif dye. Hassaan dkk. (2017) menyatakan bahwa proses oksidasi zat pewarna direct blue 86 yang dilakukan pada $\mathrm{pH}$ 11, menggunakan ozon $\left(\mathrm{O}_{3}\right)$ efektif mendegradasi zat pewarna (konsentrasi $100 \mathrm{ppm}$ ) hingga $98 \%$ pada menit ke-35. Meskipun demikian, ozon tidak efisien untuk mengurangi COD dan total senyawa organik, biasanya tidak melebihi 50 dan $40 \%$ (Shriram dan Kanmani, 2014). Proses biodegradasi menggunakan mikro organisme untuk mengubah polutan atau senyawa kimia menjadi senyawa yang lebih sederhana dengan tingkat toksisitas yang lebih rendah. Penelitian yang dilakukan oleh Agil dan Sutariningsih (2016) menunjukkan bahwa Serratia sp., dan Klebsiella sp,. mampu mendekolorisasi zat warna indigosol sebesar $88,39 \%$. Degradasi zat warna azo oleh bakteri Aeromonas sp., Pseudomonas sp., dan Flavobacterium sp,. dalam kondisi anaerob lebih cepat dibandingkan aerob, namun demikian dihasilkan amina aromatik yang bersifat lebih toksik dibanding zat warna itu sendiri (Sastrawidana dkk., 2012).

Salah satu metode yang telah dikembangkan untuk mendegradasi pewarna limbah dengan meningkatkan tegangan operasi hingga membentuk plasma melalui prinsip elektrolisis konvensional adalah metode Elektrolisis Plasma. Plasma adalah gas terionisasi akibat lucutan elektromagnetik dan menghasilkan radikal hidroksil $(\bullet \mathrm{OH})$ dalam jumlah lebih banyak dibandingkan metode lain (Saksono dkk., 2014). Radikal hidroksil merupakan oksidator terkuat yang dapat mengoksidasi senyawa-senyawa organik. Masa tinggal $\bullet \mathrm{OH}$ sangat singkat disebabkan karena sifatnya yang sangat reaktif dan non selektif, selain reaktif menyerang limbah organik juga mudah berekombinasi membentuk $\mathrm{H}_{2} \mathrm{O}_{2}$ (Jiang, dkk., 2014). Keberadaan $\bullet \mathrm{OH}$ dapat diketahui dengan mengukur konsentrasi $\mathrm{H}_{2} \mathrm{O}_{2}$ dalam larutan (Jin dkk., 2010). Adanya senyawa-senyawa logam seperti $\mathrm{Mn}^{2+}, \mathrm{Cu}^{2+}$, $\mathrm{Co}^{2+}, \mathrm{Fe}^{3+}$ di dalam larutan, akan mengakibatkan $\mathrm{H}_{2} \mathrm{O}_{2}$ terdekomposisi kembali menjadi $\bullet \mathrm{OH}$. Penambahan ion logam tersebut kedalam sistem reaksi akan bertindak sebagai katalis dalam mendegradasi zat pewarna (Gao dkk., 2007).

Injeksi udara pada daerah sekitar plasma mengakibatkan peningkatan produksi elektron dengan energi yang lebih tinggi, sehingga akan menghasilkan spesi aktif $\bullet \mathrm{OH}$ yang lebih banyak (Jiang dkk., 2014). Udara kurang lebih mengandung $79 \%$ nitrogen dan $21 \%$ oksigen, kandungan nitrogen pada udara yang diinjeksikan dapat membentuk spesi aktif (senyawa nitrat) yang bisa membantu proses degradasi limbah, sedangkan penambahan oksigen akan menambah spesi reaktif seperti $\mathrm{HO}_{2} \bullet$, dan $\mathrm{O} \bullet$ (Yamtake dkk., 2007). Potensial oksidasi spesi reaktif $\mathrm{HO}_{2} \bullet$ adalah $1,06 \mathrm{~V}$ dan potensial oksidasi $\mathrm{O} \cdot$ sebesar 2,42 $\mathrm{V}$ (Augusto dan Miyamoto, 2011). Berikut adalah reaksi utama antara oksigen dengan electron yang dapat menghasilkan radikal hidroksil (Yasuoka dkk., 2009):

$\mathrm{e}^{-}+\mathrm{O}_{2} \rightarrow \mathrm{O} \bullet+\mathrm{O} \bullet+\mathrm{e}^{-}$

O. $+\mathrm{H}_{2} \mathrm{O} \rightarrow \cdot \mathrm{OH}+\cdot \cdot \mathrm{OH}$

$\mathrm{e}^{-}+\mathrm{H}_{2} \mathrm{O} \rightarrow \mathrm{H} \bullet+\cdot \bullet \mathrm{OH}+\mathrm{e}^{-}$

Remazol red merupakan zat pewarna tektil dengan rumus molekul $\mathrm{C}_{27} \mathrm{H}_{18} \mathrm{O}_{16} \mathrm{~N}_{7} \mathrm{~S}_{5} \mathrm{Na}_{4} \mathrm{Cl}$ dan bobot molekul 984,2 g/mol, kelarutan dalam air $70 \mathrm{~g} / \mathrm{L}$ pada suhu 293K (Saksono dkk., 2017). Gambar 1 menunjukkan struktur molekul senyawa remazol red RB 133.

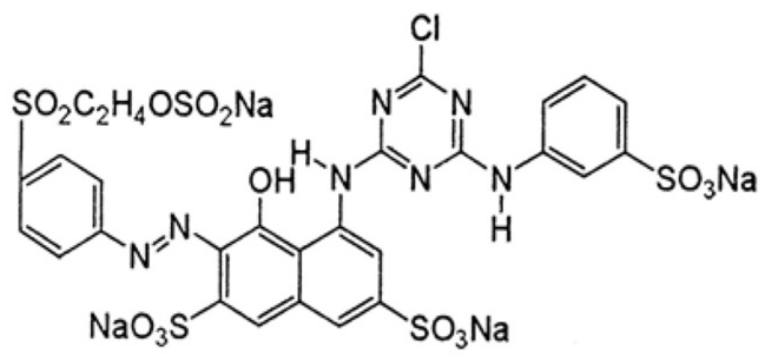

Gambar 1. Struktur molekul Remazol Red RB-133 (Saksono dkk., 2017) 


\section{Metodologi}

Penelitian ini menggunakan remazol red RRB 133 sebagai senyawa model dengan konsentrasi 100 $\mathrm{mg} / \mathrm{L}$. Volume total larutan yaitu sebanyak $1000 \mathrm{~mL}$ yang terdiri dari $\mathrm{Na}_{2} \mathrm{SO}_{4} 0,02 \mathrm{M}$ sebagai elektrolit dan ion $\mathrm{Fe}^{2+}$ sebanyak $20 \mathrm{mg} / \mathrm{L}$ sebagai katalis. Proses elektrolisis plasma dilakukan secara batch menggunakan peralatan yang diadopsi dari Liu dkk. (2010), seperti yang ditampilkan pada Gambar 2. Menggunakan satu anoda dari material tungsten dan katoda dari stainless steel SS-316, dimana anoda dilapisi oleh pirex dengan luas kontak $0,097 \mathrm{~cm}^{2}$ dan tercelup 1,5 cm kedalam larutan. Bubbler digunakan untuk membuat gelembung udara dalam larutan. Tahap awal dilakukan karakteristik arus dan tegangan untuk mengetahui tegangan optimal proses dengan dan tanpa injeksi udara. Selanjutnya dilakukan pengukuran konsumsi energi dari data arus dan tegangan. Sementara jumlah $\mathrm{H}_{2} \mathrm{O}_{2}$ didapat secara iodometri (Day dan Underwood, 2002) dan pengukuran degradasi remazol red didapat dengan metode spektrofotometri menggunakan spektrofotometer UV-Vis merk Bell pada panjang gelombang $(\lambda) 510 \mathrm{~nm}$.

\section{Hasil dan Pembahasan}

3.1. Pengaruh suhu terhadap titik breakdown dan titik kritis

Gambar 3 memperlihatkan profil kurva karakteristik arus-tegangan pada suhu $55{ }^{\circ} \mathrm{C}$ tanpa injeksi udara. Kurva tersebut menunjukkan adanya tiga zona (Lu dkk., 2011), yaitu zona ohmic ( $0<\mathrm{V}<$ $\mathrm{V}_{\mathrm{B}}$ ), zona transisi $\left(\mathrm{V}_{\mathrm{B}}<\mathrm{V}<\mathrm{V}_{\mathrm{D}}\right)$ dan zona glow discharge $\left(\mathrm{V}>\mathrm{V}_{\mathrm{D}}\right)$. Zona ohmic ditandai dengan adanya peningkatan arus yang sebanding dengan peningkatan tegangan yang digunakan. Pada zona ini terjadi elektrolisis konvensional (elektrolisis Faraday). Peristiwa elektrolisis pada air ditandai dengan munculnya gelembung-gelembung gas di sekitar anoda. $\mathrm{V}_{\mathrm{B}}$ dinyatakan sebagai breakdown voltage (Marcucci dkk., 2002). Pada zona ohmic, nilai $V_{B}$ adalah sebesar $240 \mathrm{~V}$ dengan menggunakan arus $\mathrm{I}_{B}$ (breakdown current) sebesar 1,18 A, energi yang digunakan pada proses ini sebesar $284,58 \mathrm{~kJ} /$ detik.

Pada zona transisi, terjadi penurunan arus yang berbanding terbalik dengan peningkatan tegangan yang digunakan. Hal ini disebabkan oleh terbentuknya selubung gas di sekitar anoda yang mengakibatkan terjadinya pembentukan gelembung udara sehingga arus menurun (Lu dkk., 2011 dan Marcucci, dkk., 2002). Bertambahnya gelembung yang dihasilkan akan mempengaruhi kestabilan zona ini, hal ini ditandai oleh semakin berfluktuatifnya arus yang dihasilkan.

Pada zona glow discharge, arus meningkat dengan bertambahnya tegangan yang diberikan, sementara plasma yang dihasilkan juga semakin besar. $\mathrm{V}_{\mathrm{D}}$ (critical voltage) pada zona ini sebesar 540 volt dengan arus $\mathrm{I}_{\mathrm{D}}$ (critical current) sebesar 0,78 A, yang mengkonsumsi energi sebesar $422,38 \mathrm{~kJ} / \mathrm{det}$.

Selubung gas terbentuk ketika laju pembentukan gas di elektroda mencapai nilai kritis, mengakibatkan ketidakstabilan, laju gelembung gas dapat menghancurkan batas antara permukaan gas-cair maka gelembung membentuk continous selubung gas (Sengupta dkk., 1997). Fenomena plasma ditandai dengan adanya penurunan drastis arus listrik yang ditunjukkan dengan munculnya selubung gas yang berpendar pada elektroda (Sengupta dan Singh, 1991). Tabel 1 memperlihatkan bahwa dengan meningkatnya suhu proses, maka nilai $V_{B}$ semakin menurun. Ini menunjukkan bahwa dengan semakin mudah terbentuknya selubung gas, maka pembentukan plasma juga akan semakin mudah. Selain itu, seiring dengan meningkatnya suhu, nilai dari $\mathrm{I}_{\mathrm{B}}$ dan energi juga akan semakin menurun. Hal ini disebabkan oleh semakin mudahnya pembentukan selubung gas akibat evaporasi $\mathrm{H}_{2} \mathrm{O}$ sebagai dampak dari joule heating effect, yang dipengaruhi oleh konfigurasi elektroda, sumber arus serta konduktivitas larutan elektrolit (Saito dkk., 2015). Dengan meningkatnya suhu proses, energi yang dibutuhkan untuk proses penguapan menjadi kecil. Sementara kebutuhan energi untuk proses penguapan sendiri menurut Baspalko mencapai $95 \%$ dari total energi proses (Baspalko, 2014).

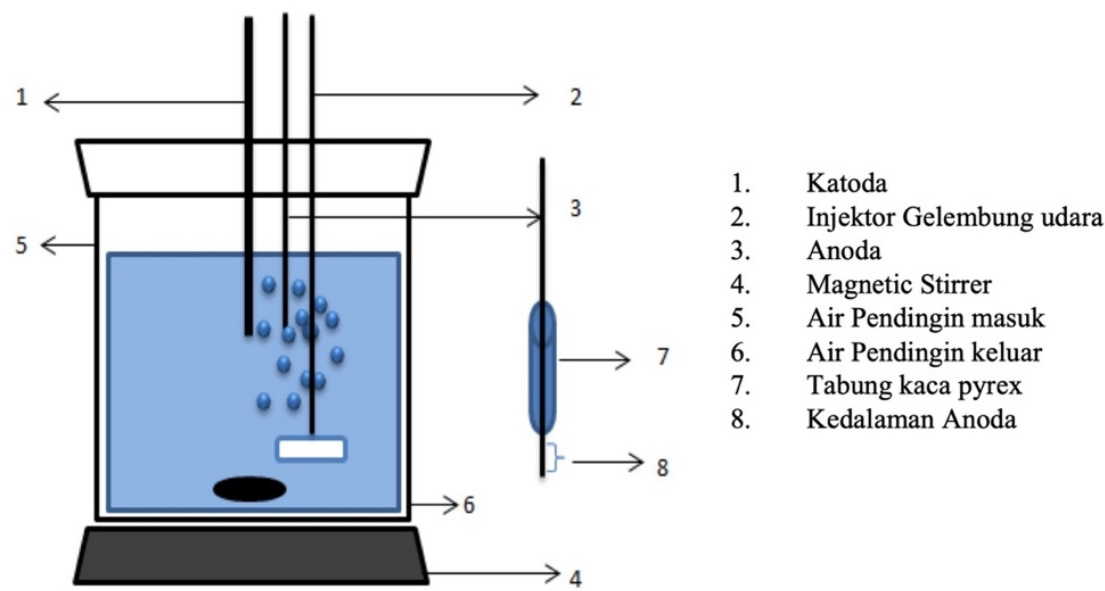

Gambar 2. Skema diagram reaktor Elektrolisis Plasma untuk mengolah limbah zat warna Remazol Red RB-133 
Pada zona $\mathrm{V}_{\mathrm{D}}$, dengan bertambahnya suhu proses, $V_{D}$ cenderung semakin menurun. Hal ini menunjukan, bahwa dengan kenaikan suhu proses, pembentukan plasma secara sempurna semakin mudah. Arus $\mathrm{I}_{\mathrm{B}}$ dan energi juga semakin menurun, seiring meningkatnya suhu. Ini mengindikasikan bahwa dengan bertambahnya suhu, dibutuhkan lebih sedikit energi untuk menstabilkan plasma.

Pada zona $V_{D}$, dengan bertambahnya suhu proses, $\mathrm{V}_{\mathrm{D}}$ cenderung semakin menurun. Hal ini menunjukan, bahwa dengan kenaikan suhu proses, pembentukan plasma secara sempurna semakin mudah. Arus $I_{B}$ dan energi juga semakin menurun, seiring meningkatnya suhu. Ini mengindikasikan bahwa dengan bertambahnya suhu, dibutuhkan lebih sedikit energi untuk menstabilkan plasma.
3.2. Pengaruh injeksi udara terhadap kurva karakteristik arus-tegangan serta breakdown point dan critical point

Kurva karakteristik arus - tegangan dibuat dengan membandingkan hasil antara proses yang dilakukan dengan dan tanpa adanya injeksi gelembung udara (Gambar 4). Proses dilakukan pada suhu $45^{\circ} \mathrm{C}$ dengan kedalaman anoda sebesar 1,5 cm. Gambar 4 menunjukkan bahwa nilai $V_{B}$ dan $V_{D}$ pada proses Elektrolisis Plasma dengan injeksi udara lebih kecil dibandingkan tanpa injeksi udara. Dengan adanya gelembung gas, pencabangan dari lucutan lebih mudah tersebar dan lebih panjang dibandingkan dengan tanpa gelembung gas. Hal ini disebabkan oleh densitas medium pada gelembung gas jauh lebih rendah dibandingkan dengan cairan (Ruma dkk., 2015). Adanya penambahan gelembung udara ke dalam larutan memudahkan pembentukan plasma.

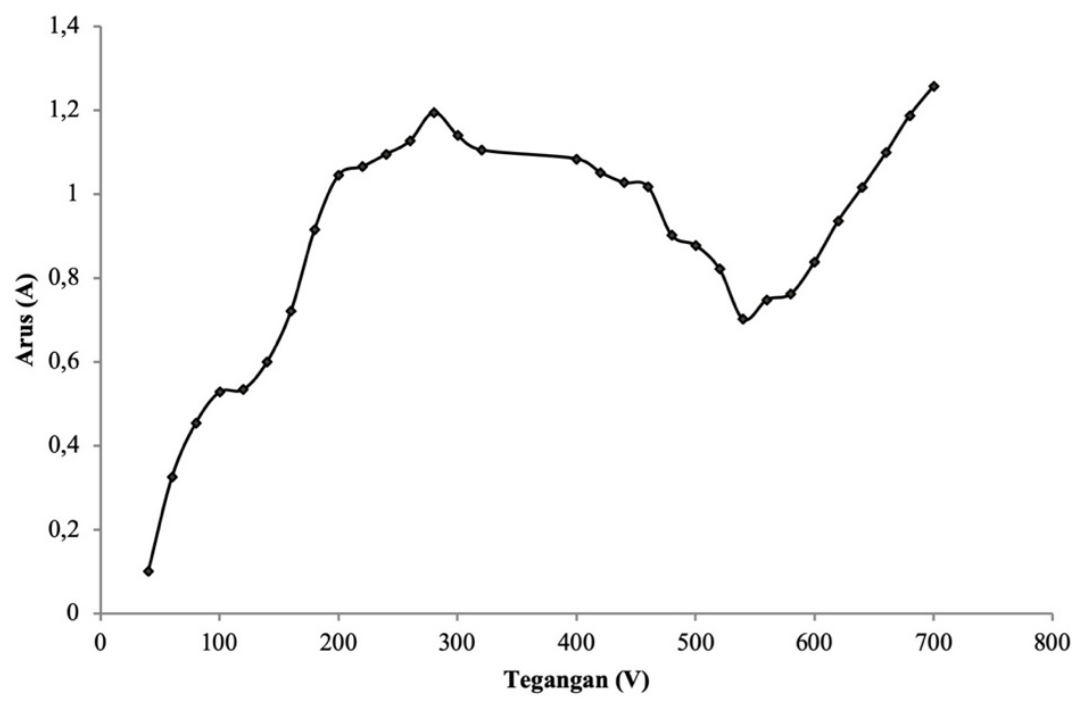

Gambar 3. Kurva karakteristik Arus-Tegangan, suhu $55^{\circ} \mathrm{C}$

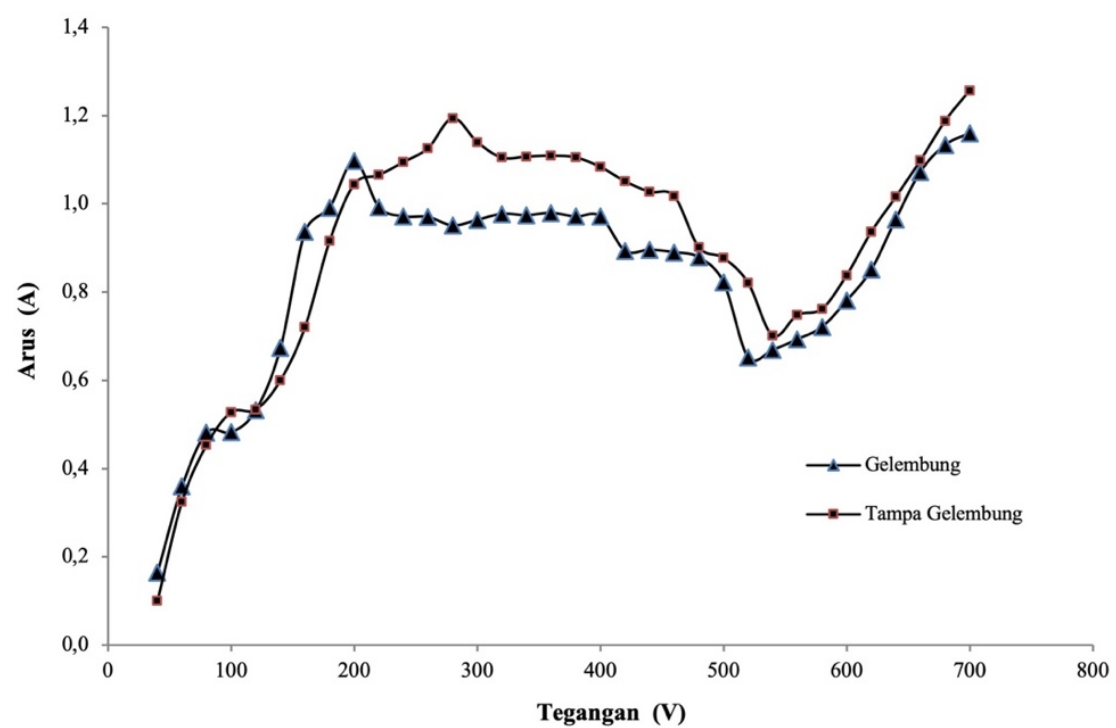

Gambar 4. Pengaruh gelembung udara (injeksi udara) pada kurva karakteristik Arus-Tegangan 
Tabel 2, menunjukkan perbandingan nilai $\mathrm{V}_{\mathrm{B}}, \mathrm{V}_{\mathrm{D}}$, $\mathrm{I}_{\mathrm{B}}, \mathrm{I}_{\mathrm{D}}$, dan energi dengan dan tanpa injeksi udara. Pada kondisi breakdown voltage $\left(\mathrm{V}_{\mathrm{B}}\right)$, dengan adanya gelembung udara, proses pembentukan selubung gas dimana plasma terbentuk akan lebih mudah, sehingga nilai $V_{B}$-nya akan lebih kecil dibanding tanpa gelembung. Penambahan gelembung udara, dapat menstabilkan selubung gas, sehingga plasma lebih mudah terbentuk. Akibatnya konsumsi energi untuk pembentukan plasma akan berkurang secara signifikan. Jyoti dkk. (2001) menyatakan bahwa injeksi udara memiliki efisiensi yang sangat tinggi dibandingkan dengan tanpa injeksi. Dalam medium air murni, dibutuhkan $V_{B}$ yang lebih tinggi disebabkan oleh kekuatan dielektrik air yang tinggi. Penambahan gas dan dihasilkannya gelembung-gelembung gas serta selubung gas mengarah pada penurunan $\mathrm{V}_{\mathrm{B}}$. Hal ini disebabkan karena konstanta dielektrik gas lebih kecil dibandingkan cairan (Ahmed, dkk., 2016).

Pada kondisi $V_{D}$, injeksi udara akan mengurangi konsumsi energi. Meskipun demikian, jika dibandingkan dengan kondisi $\mathrm{V}_{\mathrm{B}}$, efek injeksi udara tidak terlalu signifikan. Hal ini disebabkan karena pada kondisi $V_{D}$ plasma yang terbentuk sudah sempurna, sehingga injeksi udara tidak terlalu berpengaruh terhadap $\mathrm{V}_{\mathrm{D}}$ dan $\mathrm{I}_{\mathrm{D}}$.

Arus yang digunakan pada kondisi $V_{B}$ dan $V_{D}$ akan lebih kecil dengan adanya injeksi udara (Tabel 2). Selain itu energi pembentukan plasma juga akan lebih rendah. Gelembung gas eksternal dapat mempengaruhi aktivitas kimia plasma sama halnya seperti produksi radikal atau molekul reaktif. Selain itu, gelembung gas pada air dapat menurunkan medan elektrik yang dibutuhkan untuk lecutan (discharge) awal, sehingga mampu mereduksi erosi elektroda, sebuah permasalahan yang umum ditemui pada metode discharge langsung. Kelebihan lainnya dari metode gelembung pada lecutan air yaitu mudahnya inisiasi awal dari ionisasi dan proses pergeseran elektron, yang mempengaruhi pembentukan spesies aktif dan mengurangi joule heating effect akibat penguapan (Ruma dkk., 2015).

\subsection{Efek Injeksi udara dan suhu terhadap produksi $\bullet \mathrm{OH}$ dan energi \\ Tabel 3 menunjukkan injeksi udara pada proses} Elektrolisis Plasma akan memudahkan terbentuknya selubung gas, sehingga pembentukan plasma menjadi lebih mudah. Dengan demikian, energi yang dibutuhkan untuk evaporasi menjadi lebih rendah sehingga efisiensi proses menjadi lebih baik. Hal itu dapat dilihat dari lebih kecilnya energi yang dibutuhkan pada proses injeksi udara. Oleh karena itu, $V_{B}$ yang rendah dibutuhkan pada konduktivitas yang lebih tinggi. Gelembung dan selubung gas mengurangi $\mathrm{V}_{\mathrm{B}}$ akibat kekuatan dielektrik gas jauh lebih kecil dari air. Oleh karena itu, input yang dibutuhkan untuk $V_{B}$ menjadi lebih tinggi pada medium air murni dibandingkan dengan medium yang terinjeksi gas (Ahmed dkk., 2016).

Tabel 1. Pengaruh suhu proses terhadap nilai $V_{B}, I_{B}, V_{D}, I_{D}$, dan energi menggunakan metode Elektrolisis Plasma dengan injeksi udara dan kedalaman anoda $1,5 \mathrm{~cm}$

\begin{tabular}{ccccccc}
\hline T $\left({ }^{\circ} \mathrm{C}\right)$ & \multicolumn{3}{c}{ Breakdown Point } & \multicolumn{2}{c}{ Critical Point } \\
\cline { 2 - 6 } & V B (Volt) & I $(\mathrm{A})$ & Energi (J/det) & V (Volt) & ID (A) & Energi (J/det) \\
\hline 45 & 240 & 1,18 & 284,58 & 540 & 0,78 & 422,38 \\
55 & 200 & 1,09 & 219,45 & 520 & 0,65 & 339,11 \\
65 & 200 & 0,99 & 198,29 & 520 & 0,54 & 285,06 \\
75 & 180 & 0,88 & 159,95 & 520 & 0,47 & 244,73 \\
\hline
\end{tabular}

Tabel 2. Efek Injeksi Udara Terhadap Nilai $V_{B}, I_{B}, V_{D}$, $I_{D}$, dan Konsumsi Energi

\begin{tabular}{lcccccc}
\hline Metode & \multicolumn{3}{c}{ Breakdown Voltage } & \multicolumn{2}{c}{ Critical Voltage } \\
\cline { 2 - 6 } & $\mathrm{V}($ volt) & $\mathrm{I}(\mathrm{A})$ & Energi J/det & $\mathrm{V}(\mathrm{volt})$ & $\mathrm{I}(\mathrm{A})$ & Energi (J/det) \\
\hline Injeksi Udara & 240 & 1,185 & 284,4 & 540 & 0,7822 & 422,385 \\
Tanpa Injeksi udara & 300 & 1,197 & 359,1 & 560 & 0,8419 & 471,464 \\
\hline
\end{tabular}

Tabel 3. Efek Injeksi udara terhadap produksi $\mathrm{H}_{2} \mathrm{O}_{2}$ dan konsumsi energi

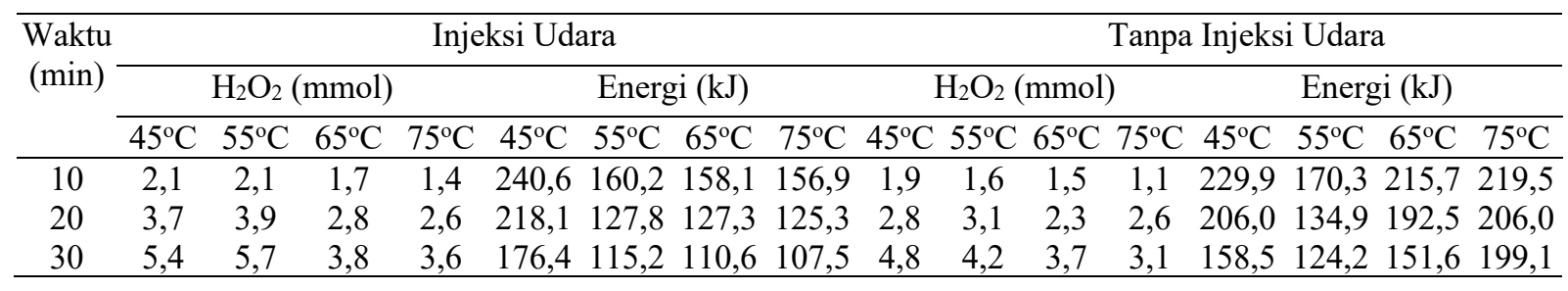


Dari sisi produksi $\bullet \mathrm{OH}$, adanya gelembung udara akan memperbesar interaksi antara $\mathrm{O}_{2}$ yang terkandung dalam udara dengan spesi reaktif, sehingga produksi - OH menjadi lebih besar (Yamtake dkk., 2007). Molekul-molekul gas akan memiliki energi saat lecutan plasma terbentuk ketika diinjeksikan gelembung gas pada selubung plasma. Hal ini mengakibatkan adanya peningkatan produksi radikal reaktif pada area yang terkontak (Ruma dkk., 2015). Dengan meningkatnya produksi $\bullet \mathrm{OH}$, maka efisiensi proses menjadi lebih baik.

Tabel 3 memperlihatkan dengan meningkatnya suhu, maka produksi $\mathrm{H}_{2} \mathrm{O}_{2}$ menurun. Hasil penelitian menunjukkan pada suhu $55{ }^{\circ} \mathrm{C}$ dengan injeksi udara dihasilkan $\mathrm{H}_{2} \mathrm{O}_{2}$ yang optimum. Hal ini kemungkinan disebabkan karena dengan meningkatnya suhu maka $\mathrm{H}_{2} \mathrm{O}_{2}$ yang terbentuk dari $\bullet \mathrm{OH}$ dapat terdekomposisi menjadi $\mathrm{H}_{2} \mathrm{O}$ dan $\mathrm{O}_{2}$ (Yazici dan Deveci, 2010). Energi pembentukan plasma dipengaruhi oleh suhu, semakin tinggi suhu proses, maka kebutuhan energi proses semakin menurun. Hal ini berhubungan dengan penurunan energi evaporasi dalam proses pembentukan plasma yang menurun, seiring dengan dengan peningkatan suhu, Baspalko (2014) menyatakan bahwa peningkatan suhu proses akan menurunkan konsumsi energi pembentukan plasma (Baspalko, 2014).

\subsection{Pengaruh injeksi udara terhadap Penyisihan Remazol Red}

Selama berlangsungnya proses elektrolisis plasma, akan dihasilkan $\bullet \mathrm{OH}$ yang berperan sebagai oksidator kuat yang akan mendegradasi senyawa remazol red dalam larutan. Tabel 4 menunjukan pengaruh injeksi udara terhadap penyisihan Remazol Red $R B$ 133. Proses penyisihan berlangsung cepat sekitar $86 \%$ pada 6 menit pertama karena jumlah senyawa remazol red masih sangat banyak, sehingga - OH dapat bereaksi secara cepat dengan limbah pewarna. Untuk selanjutnya proses penyisihan akan berjalan lambat baik dengan ataupun tanpa adanya injeksi gelembung udara. Hal ini disebabkan oleh rendahnya konsentrasi remazol red dalam larutan, sehingga menyulitkan senyawa ini untuk didegradasi. Akibat sedikitnya jumlah limbah serta waktu tinggal $\bullet \mathrm{OH}$ yang singkat, yaitu 3,7 x $10^{-9}$ detik, maka $\bullet \mathrm{OH}$ akan berekombinasi dengan sesama membentuk $\mathrm{H}_{2} \mathrm{O}_{2}$ (Jiang dkk., 2014)

Tabel 4. Pengaruh injeksi udara terhadap penyisihan Remazol Red

\begin{tabular}{ccc}
\hline Waktu (menit) & \multicolumn{2}{c}{ \% Penyisihan } \\
\cline { 2 - 3 } & Injeksi & Tanpa Injeksi \\
\hline 0 & 0,00 & 0,00 \\
6 & 86,92 & 86,13 \\
20 & 88,43 & 87,03 \\
30 & 88,91 & 87,34 \\
\hline
\end{tabular}

Tabel 4 menunjukkan tidak terjadi peningkatan penyisihan yang signifikan dengan adanya injeksi udara, sementara di Tabel 3 Injeksi udara siginifikan meningkatkan produksi $\bullet \mathrm{OH}$. Hal ini disebabkan pada konsentrasi limbah yang sudah rendah (persen peyisihan diatas $80 \%$ ) maka $\bullet \mathrm{OH}$ yang terbentuk akan lebih menyukai reaksi rekombinasi sesama $\bullet \mathrm{OH}$ membentuk $\mathrm{H}_{2} \mathrm{O}_{2}$ (Jiang, dkk., 2014), sehingga meskipun terjadi penambahan produksi $\bullet \mathrm{OH}$ pada penambahan gelembung udara, namun tidak menyebabkan peningkatan yang berarti pada degradasi limbah. Untuk dapat mengamati pengaruh $\bullet \mathrm{OH}$ terhadap peyisihan maka Perlu dilakukan pengamatan pada 60 detik pertama reaksi, dimana konsentrasi limbah masih cukup tinggi.

\section{Kesimpulan}

Penelitian ini telah berhasil menyisihkan limbah zat pewarna tekstil remazol red RB 133 menggunakan metode Elektrolisis Plasma. Konsumsi energi pembentukan plasma menurun dengan meningkatnya suhu larutan. sementara pada injeksi udara, produksi optimal radikal hidroksil dicapai pada suhu $55{ }^{\circ} \mathrm{C}$. Injeksi udara pada larutan menunjukkan penurunan konsumsi energi dan peningkatan produksi $\mathrm{H}_{2} \mathrm{O}_{2}$. Sementara untuk penyisihan limbah pewarna Remazol Red 133 tidak terjadi peningkatan yang signifikan.

\section{Ucapan Terima kasih}

Riset ini sebagian dibiayai oleh Hibah PUDPT RISTEK DIKTI No kontrak NKB1786/UN2.R3.1/HKP.05.00/2019.

\section{Daftar Pustaka}

Agil, M.; Sutariningsih, E., Dekolorisasi Pewarna Indogosol oleh Bakteri Tanah, Prosiding Symbion (Symposium on Biology Education), Yogyakarta, 27 Agustus, 2016.

Ahmed, M.; Suresh, R.; Keun Yang. J; Choi. S.; Lee, H., Effect of Water Conductivity on the Generation of -OH Radicals in High Frequency Underwater Capillary Discharge. International Journal of Renewable Energy and Environmental Engineering, 2016, 4(3), 28-34.

Augusto, O.; Miyamoto, S., Oxygen Radicals and Related Species. Pantopoulos, K., Schipper, H.M., eds. Principles of Free Radical Biomedicine, Nova Biomedical Press, 2011, Vol. 1, pp. 1-22.

Day; Underwood, Analisa Kimia Kuantitatif. Jakarta: Penerbit Erlangga, 2002.

Gao, J.; Guo, X.; Ma, D.; Yang, W., The Role of Fe (II) in the Contact Glow Discharged Electrolysis, Plasma Science and Technology. Plasma Science and Technology, 2007, 9(04), 430-435.

Hassaan, M.; Ell Nemr A.; Madkour F.F., Testing the Advanced Oxidation Proceeeses on the Degradation of 
Direct Blue 86 Dye in Wastewater. Egyptian Journal of Aquatic Research, 2017, 43(1), 11-19.

Jiang, B.; Zheng, J.; Qiu, S.; Wu, M.; Zhang, Q.; Yan, Z.; Xue, Q., Review on Electrical Discharge Plasma Technology for Wastewater Remediation. Chemical Engineering Journal, 2014, 236, 348-368.

Jin, X.; Wang, X.; Yue, J.; \& Cai, Y., The Effect of Electrolysis Constituents on Contact Glow Discharge Electrolysis. Electrochimica Acta, 2010, 56, 925-928. Jyoti, K.K.; Pandit, A.B., Water Disinfection by Acoustic and Hydrodynamic Cavitation. Biochemical Engineering Journal, 2011, 7(3), 201-212.

Khairy, M.; Kamal, B.; Amin, N.H.; Mousa, M.A., Kinetic and Isoterm Studies of Remazol Red Adsorption onto Polyaniline/Cerium Oxide Composites. Journal of Basic and Environmental Sciences 3, 2016, 2016, 123-132.

Lau, Y.; Wong, Y.S.; Teng, T.T.; Morad, N.; Rafatullah, M.; Ong, S.A., Degradation of Cationic and Anionic Dyes in Cagulation-Flocculation Process using Bi-functionalized Silica Hybrid with AluminumFerric as Auxiliary Agent. Journal Royal Society of Chemistry, 2015, 5, 34206-34215.

Liu, Y.; Wang, D.; Sun, B.; Zu, X., Aqueous 4nitrophenol Decomposition and Hydrogen Peroxide Formation Induced by Contact Glow Discharged Electrolysis. Journal of Hazardous Materials, 2010, 181(1-3), 1010-1015.

Lu, Q.; Yu, J.; Gao, J.; Yang, W.; Li, Y., Glow-discharge Electrolysis Plasma Induced Synthesis of Polyvinylpyrrolidone/Acrylic Acid Hydrogel and its Adsorption Properties for Heavy-metal Ions. Plasma Processes and Polymers, 2011, 8(9), 803-814.

Manurung R.; Hasibuan, R.; Irvan, Perombakan, Zat Warna Azo Reaktif secara Anaerob-Aaerob. Prosiding Jurusan Teknik Kimia Universitas Sumatera Utara, Medan, 11 Oktober 2004.

Marcucci, M.; Ciardelli, G.; Matteucci, A.; Ranieri, L.; Russo, M., Experimental Campaigns on Textile Wastewater for Reuse by Means of Different Membrane Processes. Desalination, 2002, 149(1), 137-143.

Ogugbue, C.J.; Sawidis T., Bioremediation and Detoxification of Synthetic Wastewater Containing Triarylmethane Dyes by Aeromonas hydrophila Isolated from Industrial Effluent. Biotechnology Research International, 2011, 2011, 1-11.

Ruma; Habib, M.A.; Hosseini, S.H.R.; Sakugawa, T.; Akiyama, H., Treatment of Wastewater by Underwater
Discharge in Gas Bubbling Water. International Journal of Renewable Energy and Environmental Engineering, 2015, 03(03), 189-194.

Saksono, N.; Nugraha, I.; Gozan, M.; Bismo, S.; Indonesia, U., Plasma Formation Energi and Hydroxyl Production on Contact Glow Discharged Electrolysis. International Journal of Arts \& Sciences, 2014, 07(03), 71-77.

Saksono, N.; Puspita, I.; Sukreni, T., Application of Contact Glow Discharge Electrolysis Method for Degradation of Batik Dye Waste Remazol Red by the Addition of $\mathrm{Fe}^{2+}$ ion. AIP Conference Proceedings, 2017, 1823, 020003.

Saito, G.; Nakasugi, Y.; Akiyama T., Generation of Solution Plasma Over a Large Electrode Surface Area, Journal of Applied Physics, 2015, 118, 023303.

Sastrawidana, I.D.K., Perombakan Air Limbah Tekstil menggunakan Jamur Pendegradasi Kayu Jenis Polyporus sp Teramobil pada Serbuk Gergaji Kayu. Jurnal Bumi Lestari, 2012, 2(02), 382-389.

Sengupta, S.K.; Singh, O.P., Contact Glow Discharge Electrolysis: A Study of Its Onset and Location. Journal of electroanalytical chemistry and interfacial electrochemistry, 1991, 301, 189-197.

Sengupta, S.K, Srivastava, A.K., Singh, R., Contact Glow Discharge Electrolysis: A Study on Its Origin in The Light of The Theory of Hydrodynamic Instabilities in Local Solvent Vaporisation by Joule Heating During Electrolysis. Journal of Electroanalytical Chemistry, 1997, 427, 23-27.

Shriram, B.; Kanmani, S., Ozonation of Textile Dyeing Wastewater-A Review. Indian Journal of Environmental Protection, 2014, 2014-15(3), 46-50.

Yazici, E.Y.; Deveci, H., Factor Affecting Decomposition of Hydrogen Peroxide. Proceedings of The XII International Mineral Processing Symposium, Cappadocia- Nevsehir, Cappadocia-Nevsehir, 6-8 October, 2010.

Yamtake, A.; Katayama, H.; Yasuoka, K.; Ishii, S., Purification by Atmospheric DC/Pulsed Plasmas Inside Bubbles in Water. International Journal of Plasma Enviromental Science \& Technology, 2007, 1(1), 9195.

Yasuoka, K.; Sato, K., Development of Repetitive Pulsed Plasmas in Gas Bubbles for Water Treatment. International Journal of Plasma Environment Science and Technology, 2009, 3(1), 22-27. 